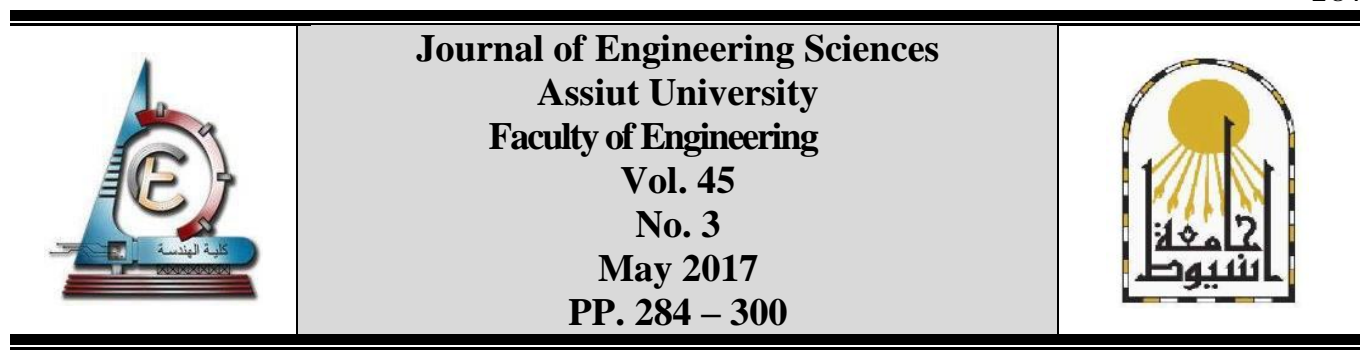

\title{
DAMAGE ANALYSIS OF INELASTIC STRUCTURES UNDER TRAIN-INDUCED VIBRATIONS
}

\author{
Abbas Moustafa ${ }^{1}$, Alshaymaa Ameen ${ }^{2, *}$ \\ ${ }^{1}$ Department of Civil Engineering, Minia University \\ ${ }^{2}$ Department of Civil Engineering, Luxor High Institute of Engineering
}

Received 9 March 2017; Accepted 27 April 2017

\begin{abstract}
This paper deals with response analysis of inelastic simple engineering structures under high-speed train-induced vibration. The dynamic load is represented as a time-variant pulse-train function of unequal amplitudes. The structural response is quantified in terms of ductility factor, permanent deformation, number of cyclic loops, and input, hysteretic and damping energies. Measures of the structural performance based on energy concepts and damage indices are also considered. Specifically, the structural performance is quantified in terms of Park and Ang damage index. Damage indices imply that the structure is damaged by a combination of repeated stress reversals and high-stress excursions. In fact, the use of damage indices provides a measure on the structural damage level and required repair. A new scalar index based on Park and Ang and Cosenza and Fajfar damage indices is also proposed in this paper. The formulation is demonstrated by studying the structural response of single-degree-of-freedom inelastic structure to pulse train load composed of locomotive and 10 coaches. A computational code is developed in the Matlab platform to illustrate the numerical results.
\end{abstract}

Keywords: Damage index; ductility ratio; hysteric energy; inelastic structure; input energy; train-induced vibration.

\section{Introduction}

Structural damage prevention from train- and vehicle-induced vibration remains a key problem for engineers nowadays. This is particularly true for railway and vehicle bridges and buildings adjacent to railways, since such structures are always subjected to repeated osscilations during passage of heavy vehicles and high-speed trains. Trains emit not only noise but also vibration, and the influence of vibration is poorly understood. The effect of train noise and vibration on human was discussed [1]. [2] Hans et al. (2016) provide practical experience of performing measurements nearby railway lines and describes a method that can be used in order to obtain reliable results with a statistical approach. Vibrations induced by high-speed trains are dynamic loads similar to earthquake and blast loads. However, characteristics of each of these loads (e.g., frequency content, amplitude, time duration, etc.) are different. The total duration for a blast load due to a chemical

* Corresponding author.

Email address: shosho_elshaikh74@yahoo.com 
explosion is about 0.001-0.1 s, while that for an earthquake is about 20-50 s and the total duration from a high-speed train lies between these two barriers (2-10 s) for instance. Furthermore, train-induced loads have positive amplitudes while blast and earthquake loads have positive and negative amplitudes. [3] presented a comprehensive state-of-the-art review on train-induced vibration. The study discusses various impact criteria, building damage, vibration measurement, control of groundborne noise/vibration and evaluation techniques. Which include wheel and rail maintenance, track support system design, resilient wheels, tunnel wall thickness, floating slabs, trenches and building isolation? The study investigates resiliently supported ties, floating slabs, tracks, subway/soil interaction, and radiation from the subway structure, vibration propagation, and attenuation in soil and building response to ground borne vibration.

Train-induced vibrations on bridges are transmitted directly to the structural members with almost same amplitude and frequency. If the buildings located close to railways, the soil medium amplifies amplitudes and filters frequency content of train-induced vibration before they hit nearby buildings. A theoretical study on 3D wave propagation in layered soil is reported [4]. Experimental results of hammer (impulse), harmonic and railway traffic excitation are also presented by the same author. The ground vibration is assumed to consist of primarily Rayleigh waves induced by moving forces on rough roads propagating along the surface of an elastic homogeneous half-space.

A numerical model of free-field traffic-induced vibrations during the passage of a vehicle on an uneven road accounting for the dynamic interaction between the road and the soil using the dynamic substructure method and the boundary element technique is developed [5]. The model is validated with analytical results and numerical illustrations for free-field vibration during passage of a vehicle on a traffic plateau. Understanding train vibration from their origin and associated structural response remains an active area of research. In reality, the process of train vibration transmitted to the structure such as bridges and nearby buildings is energy transferring process. Energy is produced by oscillation of the ground due to train-induced vibration, and the movement of the ground transfers ground shaking as input energy to the structure. This input energy is then transformed into different forms of energies dissipated by the structure (strain, kinetic and damping energies) inducing soil settlement and structural damage [6] and [7]. Hence, it is crucial to understand the energy characteristics and energy transfer and associated structural damage due to train-induced vibration.

The rapid increase of high-speed train lines, especially throughout Europe, East-Asia and some African countries, has recently stimulated researchers to develop and calibrate predictive tools for analysis of ground vibrations induced in the vicinity of railways. Excessive ground vibrations may have a significant impact on human comfort and on the built environment. Due to rapid urbanization, more buildings are constructed closer to busy roads and railways. [8] analyzed the response of five hypothetical reinforced concrete structures subjected to field measured ground motions caused by normal traffic conditions and discussed the effect of traffic induced ground motions on safety of building structures adjacent to busy roadways. This study focused on human and normal operation of sensitive equipment housed in buildings.

Vertical ground motion induced by a moving train is one of the major sources of environmental loads that affect the normal operation of sensitive equipment installed in high technology buildings nearby railways. [9] investigated the micro vibration level of a high technology building subjected to nearby train-induced vertical ground motion and its mitigation using a hybrid control platform for sensitive equipment. [10] compared the use 
of local and global shape functions in a boundary element method used in a prediction model for traffic-induced vibrations. Vibration levels have been predicted using a vehicle model and related to measured values [11]. A method of calculating the wave field of horizontally layered soils was presented [12]. An entirely analytical method of calculating the power spectrum density function of ground vibration in vicinity of a busy roadway is presented [13]. [14] developed a closed form analytical model for traffic-induced ground vibrations expressing excitation as a random process using power spectral density.

[15] used the finite element method to simulate ground vibrations transmitted from a road on a layered site subjected to harmonic forces. [16] utilized the boundary element method to deal with the numerical modeling of free field vibrations induced during the passage of a vehicle using the dynamic substructure method. The dynamic response of a simply supported, single-span structure during the passage of a train modeled by the EulerBernoulli beam theory under constant moving loads was studied [17]. This elementary, yet realistic, model often gives higher vibration amplitudes than field measurements but can be refined by considering different interactions. The model can be developed by adding variation of the load where forces are time-variant functions. [18] considered axle loads to be composed of constant and harmonic components.

In general, the structural response depends on dynamic properties of the structure (natural frequency, mode shape, damping, etc.) and on characteristics of train-induced vibration (speed, frequency content, vibration amplification medium, etc.). To develop a model which includes the interaction between the train and the structure, the train can be modeled as a rigid body system. The wheels, bogies and wagon body can be modeled as separate rigid bodies, linked by dampers and springs (see, e.g., [19] and [20]). [20] investigated important parameters such as speed of the train, train-to-structure frequency ratio, mass and span ratios, structure damping and distance between axles on structural response and concluded that these parameters influence greatly the dynamic response of the structure. [21] recommends using a nonlinear stiffness law to model the interaction between the track and the structure. Most previous studies have focused on structural response, such as displacement, velocity and acceleration under train vibration. This study deals with damage of inelastic simple structures under train-induced vibration.

\section{Response of structures to train-induced vibration loads}

In this section, the response analysis and energy quantification for single-degree-offreedom (SDOF) inelastic structures under train-induced vibration is studied first. Subsequently, the use of inelastic response parameters and energy absorbed by the structure in developing damage indices is explained.

\subsection{Dynamic analysis of inelastic structures}

The equation of motion governing the relative displacement response $u(t)$ for an inelastic structure modeled as a SDOF system under train-induced vibration is given by:

$$
m \ddot{u}(t)+c \dot{u}(t)+f_{s}(t)=f(t)
$$

where $m, c$, are the mass and damping of the SDOF system, respectively, and $f_{S}(t)$ is the restoring force in the spring. The above equation of motion may describe the dynamic response of a single-story frame structure adjacent to a railway or a road or for a simple bridge model subjected to train-induced vibration $f(t)$. For linear structural behavior the 
restoring force $f_{s}(t)$ is a linear function of the displacement response $u(t)$ and the spring stiffness coefficient $k$. Whereas, in the more general case, when structural nonlinearities are considered, this force is a nonlinear function of the structure displacement and velocity. Figure 1 depicts the spring force $\mathrm{f}_{\mathrm{s}}(\mathrm{t})$ for nonlinear systems with force-displacement characteristic modeled with elastic-plastic behavior. Figure 2 shows the relationship between the inelastic deformation and the spring hysteretic force for bilinear and elasticplastic materials. Equation (1) can be rewritten as:

$$
\ddot{u}(\mathrm{t})+2 \xi \omega_{0} \dot{u}(t)+\omega_{0}^{2} u_{y} \bar{f}_{s}(t)=\frac{f(t)}{m}
$$

Here $\xi$ and $\omega_{0}$ are the pre-yield damping ratio and the pre-yield natural frequency of the structure, respectively, $u_{y}$ is the yield displacement, and $\bar{f}_{s}(t)=f_{s} / u_{y}$ is the normalized hysteric force. Equation (2) can be further recast as:

$$
\ddot{\mu}(t)+2 \xi \omega_{0} \dot{\mu}(t)+\omega_{0}^{2} \bar{f}_{s}(t)=a_{y} f(t)
$$

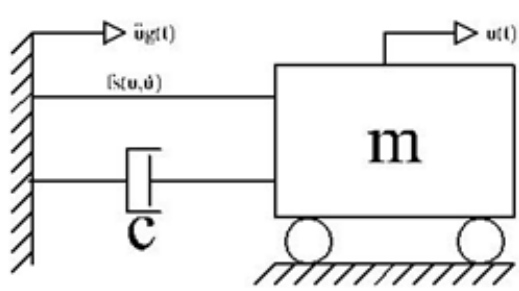

a

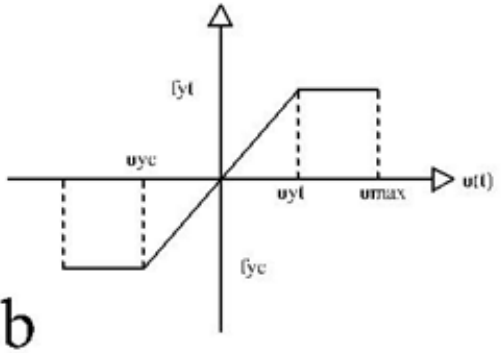

b

Fig. 1. (a) Inelastic single-degree-of-freedom system, (b) elastic-plastic behavior.

(a)

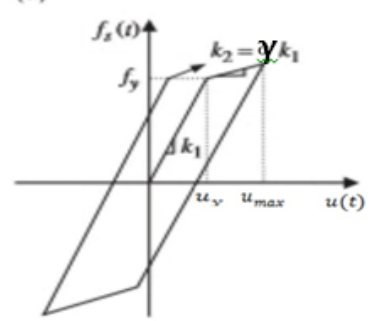

(b)

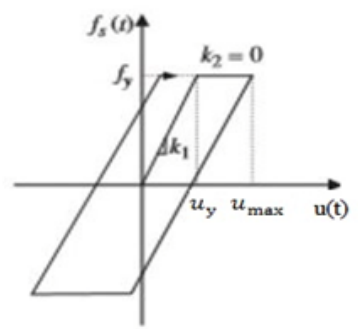

Fig. 2. Force-displacement relation for nonlinear materials: (a) bilinear model; (b) elastic-plastic model.

where $\mu(t)=u(t) / u_{y}=$ ductility ratio; and $a_{y}=\omega_{0}{ }^{2} / f_{y}=$ constant that can be interpreted as the acceleration of the mass necessary to produce the yield force. The response of inelastic SDOF structures is computed by solving the incremental form of equations (1), (2) or (3) using numerical integration at discrete points of time (e.g., Newmark $\beta$-method or Wilson- $\theta$ method). For bilinear behavior, an iterative procedure is adopted to correct for approximations of the secant stiffness used from previous time step. The next subsection demonstrates the quantification of the train-induced vibration input energy and associated energy dissipated by the inelastic structure.

\subsection{Energy dissipated by SDOF inelastic structures under train-induced vibration}

The energy balance for the SDOF inelastic structure can be obtained by multiplying equation (1) by the relative velocity $\dot{u}(t)$ and integrating with respect to time [22], [23], [24], [7], [25] and [6] as follows: 


$$
\begin{aligned}
\int_{0}^{t} m \ddot{u}(\tau) \dot{u}(\tau) d \tau+\int_{0}^{t} c \dot{u}^{2}(\tau) d \tau+\int_{0}^{t} f_{S}(\tau) \dot{u}(\tau) d \tau & =\int_{0}^{t} f(\tau) \dot{u}(\tau) d \tau \\
E_{K}(t)+E_{D}(t)+E_{S}(t) & =E_{I}(t)
\end{aligned}
$$

Equations (4a) and (4b) represent the relative energy terms (see [24] and [25]). Here $E_{I}(t)$ is the relative input energy to the structure since the structure starts to shake until it comes back to rest. $E_{K}(t)$ is the relative kinetic energy $\left[E_{K}(t)=m \dot{u}^{2}(t) / 2\right]$ and $E_{D}(t)$ is the energy absorbed by damping. The energy $E_{S}(t)$ represents the combination of the relative elastic-strain recoverable energy and the hysteretic cumulative irrecoverable (yield) energy $E_{H}(t)$. At the end of the train vibration duration the kinetic and elastic-strain energies diminish while the hysteretic energy accumulates. Thus, the train vibration input energy to the structure is dissipated by the hysteretic and the damping energies. [6] studied different forms of energy absorbed by inelastic structures under earthquake ground motion. The use of the response parameters in developing damage indices is explained hereafter.

\subsection{Damage of inelastic structures under train-induced vibration}

The literature on damage measures of structure under earthquake ground motions is vast (e.g., [26], [27] and [6]). Damage measures of structures under strong ground motion are expressed in terms of damage indices. Damage indices are based on either a single or combination of structural response parameters. [6] summarizes several damage measures that are based on a single response parameter (see, e.g., [28] and [26]). The first measure indicates the ultimate ductility produced during the ground shaking. Clearly, this measure does not incorporate any information on how the train vibration input energy is imparted on the structure nor how this energy is dissipated. Train vibration damage occurs due to the maximum deformation or ductility and associated with the hysteretic energy dissipated by the structure. The definition of structural damage, in terms of the ductility factor, is inadequate. The last three measures indicate the rate of the train vibration input energy to the structure (i.e., how fast $E_{I}$ is imparted by the train vibration and how fast it gets dissipated). Damage indices can be estimated by comparing the response parameters demanded by the train vibration with the structural capacities. [28] proposed a damage index in terms of the ultimate ductility (capacity) $\mu_{u}$ and the maximum ductility attained during ground shaking $\mu_{\max }$ :

$$
D I_{d u c}=\frac{u_{\max }-u_{y}}{u_{u}-u_{y}}=\frac{\mu_{\max }-1}{\mu_{u}-1}
$$

Since, $D I_{d u c}$ does not include effects from hysteretic energy dissipation, [26] and [29] proposed a damage index based on hysteretic energy $E_{H}$ as:

$$
D I_{C F}=\frac{E_{H} /\left(f_{y} u_{y}\right)}{\mu_{u}-1}
$$

A robust damage measure should include contribution of maximum response and repeated cyclic loading. [30], [31] and [32] developed a simple damage index, given as follows:

$$
D I_{P A}=\frac{u_{\max }}{u_{u}}+\beta \frac{E_{H}}{f_{y} u_{u}}=\frac{\mu_{\max }}{\mu_{u}}+\beta \frac{E_{H}}{f_{y} u_{y} \mu_{u}}
$$

Herein, $u_{\max }$ and $E_{H}=$ maximum displacement and dissipated hysteretic energy (excluding elastic energy) under the train vibration. Note that $u_{\max }$ is the maximum absolute value of the displacement response under ground motion, $u_{u}$ is the ultimate deformation capacity under monotonic loading and $\beta$ is a positive constant that weights the effect of cyclic loading on structural damage. The contribution to $D I_{P A}$ from cyclic loading 
Abbas Moustafa, Alshaymaa Ameen, damage analysis of inelastic structures under train-induced ....

is omitted when $\beta=0$. The state of the structural damage is defined as: (a) total or complete collapse, when $D I_{P A} \geq 1.0$, (b) damaged beyond repair, when $0.40 \leq D I_{P A}<$ 1.0 , and (c) repairable damage, when $D I_{P A}<0.40$. These criteria are based on calibration of $D I_{P A}$ against experimental results and field observations in train vibration [32]. The Park and Ang damage index reveals that both maximum ductility and hysteretic energy dissipation contribute to the structure resistance during ground motions.

A scalar index can be defined using accumulated Park and Ang damage index as follows:

$$
I_{P A}=\int_{0}^{t_{f}} D I_{P A}(\tau) d \tau
$$

Note that for small time step, equation (8) reduces to the summation of the Park and Ang damage index at discrete time points. Similarly, an energy index representing the normalized cumulative hysteretic energy developed by Fajfar and Cosenza is obtained as follows:

$$
I_{C F}=\frac{1}{f_{y} u_{y}\left(\mu_{u}-1\right)} \int_{0}^{t_{f}} E_{H}(\tau) d \tau
$$

where $\frac{1}{\boldsymbol{f}_{\boldsymbol{y}} \boldsymbol{u}_{\boldsymbol{y}}}=$ constant.

In this study, the influence of the structure's parameters such (e.g., damping ratio, strain-hardening ratio) and the characteristics of the train-induced dynamic force (e.g., train speed or total duration) on the cumulative damage indices are explored. The next section demonstrates the numerical results for the formulation developed in this study.

\section{Numerical Results and Discussions}

\subsection{Bilinear inelastic SDOF structure}

A bilinear inelastic structure is considered with mass $9 \times 10^{3} \mathrm{~kg}$, initial stiffness $\mathrm{k}_{1}=1.49 \times 10^{6} \mathrm{~N} / \mathrm{m}$ viscous damping ratio of 0.05 . The initial natural frequency was computed as $4.07 \mathrm{rad} / \mathrm{s}$ and the strain hardening ratio $\left(\mathrm{k}_{2}=\gamma \mathrm{k}_{1}\right)$ is taken as 0.05 . These parameters are changed later to study their influence on the train vibration loads and corresponding inelastic response. The yield displacement is taken as $0.01 \mathrm{~m}$ and the structure is taken to start from rest. This SDOF system may describe a simple model of a train bridge or a building structure adjacent to railways. The parameters of the Newmark $\beta$ method are taken as $\delta=0.50 ; \alpha=0.25$; and $\Delta \mathrm{t}=0.005 \mathrm{~s}$.

\subsection{Input train-induced dynamic force}

A passenger high speed train $(120 \mathrm{~km} / \mathrm{h})$ consisting of a locomotive of a total weight $w_{l}$ $=80 \mathrm{t}$ and 10 passenger coaches of weight $w_{c}=20 \mathrm{t}$ each is used to study the energy absorption and damage of inelastic SDOF structures to train-induced vibration. The locomotive consists of six axles of equal weights and the passenger coach consists of four axles of equal weights. The weights and distance between wheel axles for locomotive and coaches are demonstrated in figures (3) and (4), respectively. 


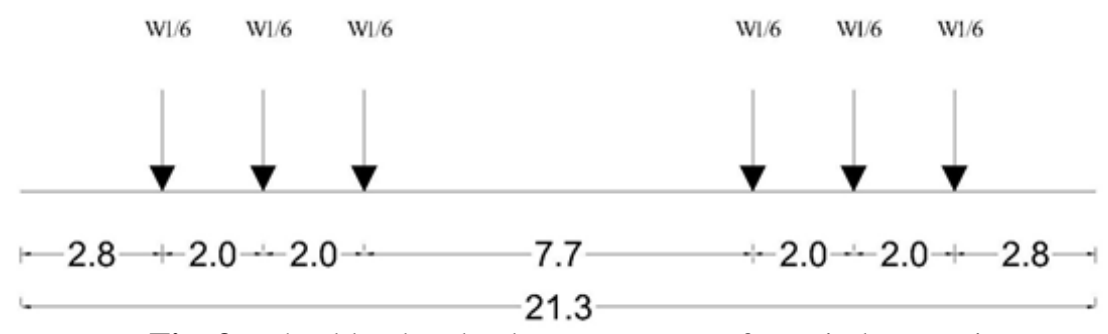

Fig. 3. Wheel load and axles arrangement for train locomotive.

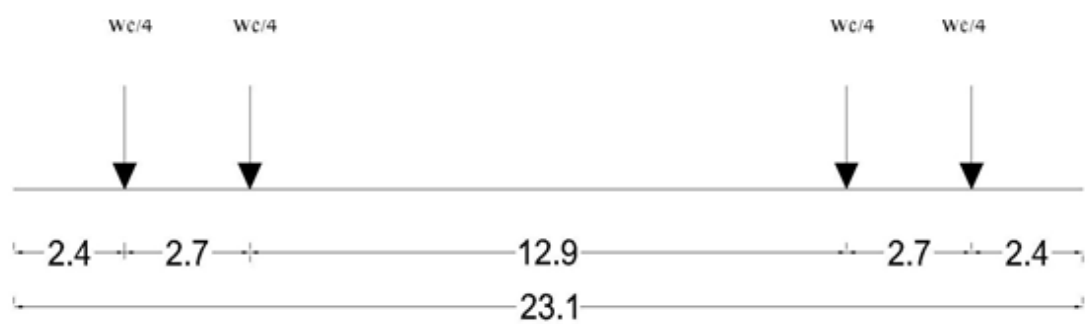

Fig. 4. Wheel load and axles arrangement for train passenger coach.

\subsection{Results and discussions}

The numerical results obtained for the SDOF structure are presented in figures 5-12 and tables 1-4. Figure 5 shows the input train acceleration and the associated structural response for inelastic structure with strain hardening ratio $=0.05$ and damping ratio $=0.05$. Figure 5 depicts the train input force, displacement response, velocity response, acceleration response, hysteretic loop and dissipated energy. Figure 6 explains the effect of the damping ratio on the structural response. Specifically, the influence of $\xi$ on the yield energy, input energy and damping energy are provided. Similar results for influence of $\xi$ on Park and Ang damage index are presented in figure 7. Figure 8 presents the effect of $\xi$ on cumulative damage index and cumulative yield energy. The effect of the change in the hardening ratio on the structural response is provided in figure 9. figures 10 and 11 provide similar results on the effect of $\gamma$ on damage indices. Based on extensive analyses of the numerical results, the following observations are made:

1. The structure responds inelastically to high-speed train-induced vibration (see table 1and figure 5-(b), 5-(e)). As the train passes close to the structure, the structure oscillates and the amplitude of vibration builds up. The inelastic structure after yielding oscillates around a new equilibrium position different from the initial equilibrium position. Each new yielding (i.e. stress reversal) causes the structure to drift from its initial equilibrium position and the system oscillates around a new equilibrium position until this gets shifted by another yielding. Accordingly, after the train passes the structure, it comes to rest at a position different from its initial equilibrium position. In other words, the structure permanent deformation remains at the end of the oscillation (see table 1 and Figure 5-(b)). For instant, the permanent deformation $\mathrm{u}_{\mathrm{p}}$ about $0.03 \mathrm{~m}$ when $\gamma=0.05$ and $\xi=0.05$. The maximum response is achieved while the structure is subjected to the train load. The displacement amplitude decays with time during the duration of the train load and decreases with permanent deformation at the end of oscillation (at time 11s) of $0.03 \mathrm{~m}$ as shown in figure 5-(b). 
2. The input energy to the structure is dissipated mainly by yielding and damping (see figure 5-(f)). The yield energy builds up faster than the damping energy. However, both energies build up cumulatively. The elastic strain energy and kinetic energy build up with time faster than other energies and approach zero by the end of the total duration of vibration. The yield energy approaches its maximum value of 183.87 N.m at around $1 \mathrm{~s}$. However the damping energy approaches its maximum value of $65.12 \mathrm{~N} \mathrm{~m}$ at time $\mathrm{t}=8 \mathrm{~s}$.

3. The increase in the damping ratio is associated with a decrease in ductility ratio, permanent and maximum deformations, maximum yield energy, maximum input energy and the number of cyclic loops or stress reversals (sees tables 1 and figure 6). For example, the ductility ratio decreases from 12.70 to $10.50(17.32 \%)$ when the damping ratio increases from 0.01 to 0.05 (see table 1). The maximum and permanent deformations decrease from $0.043 \mathrm{~m}$ to $0.035 \mathrm{~m}(17.40 \%)$, and from $0.031 \mathrm{~m}$ to $0.028 \mathrm{~m}(10.93 \%)$, respectively. The maximum yield energy decreases from about 246 N.m to about 184 N.m (25.16 \%). Similarly, the number of stress reversals decreases from 182 to $137(24.73 \%)$. Also, the increase in damping ratio is associated with a decrease in damage indices (see table 1, figure 7). Thus, when the damping ratio increases from 0.01 to 0.05 , Park and Ang damage index decreases from 1.61 to 1.33 (17.39\%), Cosenza and Fajfar damage index decreases from 0.20 to $0.16(20 \%)$ and ductility damage indices decrease from 1.67 to $1.36(18.56 \%)$. It can be observed from figure 7 that the values of Park and Ang damage index are close to associated values of ductility damage index. The values of Cosenza and Fajfar are relatively small. This could be attributed to contribution of yield energy to damage indices based on Park and Ang and ductility which is absent in damage index developed by Cosenza and Fajfar (see equations 5-7). Similarly, the cumulative damage indices decrease with increasing damping ratio (see table 2 and figure 8). Hence, when the damping ratio increases from 0.01 to 0.05 , the two proposed scalar indices decrease from 28.09 to 23.21 (17.37\%) and from 35.23 to $26.30(25.35 \%)$, respectively (see table 2$)$.

4. The increase in the strain-hardening ratio is associated with a decrease in ductility ratio, permanent and maximum deformations, maximum yield energy and number of stress reversals (see table 3 and figures 9-11). The elastic-plastic structure (i.e., $\gamma=0$ or $\mathrm{k} 2=0$ ) has larger maximum and permanent deformations, ductility factor, higher number of stress reversals and dissipates larger energy than the bilinear structure $(\gamma>0)$ (see, table $3)$. On the other hand, the increase in the strain-hardening ratio is accompanied with a decrease in all damage indices and new proposed scalar cumulative damage index (see, figures 10 and 11). Moreover, the effect of the change of strain-hardening ratio on Cosenza and Fajfar damage index is slight compared to Park and Ang damage index (see tables 3 and figure 10). As can be seen from figure 11, it can be concluded that the effect of the change in the strain hardening ratio on IPA (25.04\%) is higher than that of ICF $(19.01 \%)$. Similarly, both the input energy and the damping energy decrease as the strain-hardening ratio increases (see figures $9-(\mathrm{d}, \mathrm{e})$ ).

5. It may be noted that for the considered SDOF structure, changes in both damping ratio and strain-hardening ratio have no significant effect on damage status of the structure (total collapse since DIPA > 1.00, see tables 1 and 3). To study, influence of the initial natural frequency of the structure on the associated structural damage status, the structure natural frequency is changed and Park and Ang damage index is 
calculated. Thus, when the natural frequency of the structure changes from 12.90 $\mathrm{rad} / \mathrm{s}$ to $6.45 \mathrm{rad} / \mathrm{s}, D I_{P A}$ decreases from 1.05 to 0.35 . Accordingly, the structural damage level gets altered from total collapse to a repairable damage.

6. To investigate influence of yield strength on the structural response of SDOF inelastic structure, the value of $f_{y}$ is changed and the structural response is estimatd while all other parameters are kept unchanged. The decrease in the yield strength of the bilinear structure is seen to be accompanied with an increase in the number of hysteretic loops, yield energy and damage indices (see table 6). Thus, for $\mathrm{f}_{\mathrm{y}}=10^{4}$ $\mathrm{N}$ the damage status of the structure is repairable damage while for $\mathrm{f}_{\mathrm{y}}=5 \times 10^{3} \mathrm{~N}$, the damage status is total collapse (i.e. failure).

7. To examine influence of changing the parameter $\boldsymbol{\beta}$ on Park and Ang damage index, the value of $\boldsymbol{\beta}$ is changed keeping all other parameters constant and $D I_{\mathrm{PA}}$ is determined for each value of $\boldsymbol{\beta}$. The increase in the parameter $\boldsymbol{\beta}$ is observed to be associated with an increase in Park and Ang damage index. The variation of $D I_{\mathrm{PA}}$ and $\boldsymbol{\beta}$ is seen to be linear (see table 5 and figure 12 ).

Table 1.

Influence of damping ratio on SDOF inelastic structure response $(\gamma=0.05)$

\begin{tabular}{|c|c|c|c|c|c|c|c|c|c|c|}
\hline$\xi$ & $\mu_{\max }$ & $\begin{array}{l}u_{p} \times \\
10^{-3} \\
(m)\end{array}$ & $\begin{array}{l}u_{\max } \\
\times 10^{-3} \\
(m)\end{array}$ & $N_{r v}$ & $\begin{array}{l}E_{y \max } \\
(\boldsymbol{N} . \mathrm{m})\end{array}$ & $\begin{array}{l}E_{I \max } \\
(N . m)\end{array}$ & $\begin{array}{l}E_{D \max } \\
(N . m)\end{array}$ & $D I_{P A}$ & $D I_{C F}$ & $D I_{d u c}$ \\
\hline 0 & 13.37 & 32.30 & 44.90 & 187 & 264.69 & 294.52 & 0 & 1.70 & 0.20 & 1.77 \\
\hline 0.01 & 12.70 & 31.10 & 42.60 & 182 & 245.67 & 282.92 & 17.76 & 1.61 & 0.20 & 1.67 \\
\hline 0.02 & 11.89 & 29.60 & 39.90 & 160 & 224.54 & 268.47 & 31.29 & 1.51 & 0.19 & 1.56 \\
\hline 0.05 & 10.50 & 27.70 & 35.20 & 137 & 183.87 & 259.95 & 65.12 & 1.33 & 0.16 & 1.36 \\
\hline 0.10 & 8.27 & 22.40 & 27.80 & 93 & 135.78 & 247.41 & 104.30 & 1.05 & 0.14 & 1.04 \\
\hline
\end{tabular}

Table 2.

Influence of damping ratio on cumulative damage indices for SDOF inelastic structure $(\gamma=0.05)$

\begin{tabular}{|c|c|c|}
\hline$\xi$ & $\boldsymbol{I}_{\boldsymbol{P A}}$ & $\boldsymbol{I}_{\boldsymbol{C F}}$ \\
\hline 0 & 29.55 & 38.08 \\
\hline 0.01 & 28.09 & 35.23 \\
\hline 0.02 & 26.30 & 32.08 \\
\hline 0.05 & 23.21 & 26.30 \\
\hline 0.10 & 18.33 & 19.57 \\
\hline
\end{tabular}

Table 3.

Influence of hardening ratio on SDOF inelastic structure response $(\xi=0.05)$

\begin{tabular}{|c|c|c|c|c|c|c|c|c|c|c|}
\hline$\gamma$ & $\mu_{\max }$ & $\begin{array}{c}u_{p} \times \\
10^{-3} \\
(m)\end{array}$ & $\begin{array}{c}u_{\max } \\
\times 10^{-3} \\
(m)\end{array}$ & $N_{r v}$ & $\begin{array}{c}E_{y \max } \\
(\text { N.m) }\end{array}$ & $\begin{array}{l}E_{I \max } \\
(\mathrm{N} . \mathrm{m})\end{array}$ & $\begin{array}{c}E_{D \max } \\
(\text { N.m) }\end{array}$ & $D I_{P A}$ & $D I_{C F}$ & $\bar{D} \boldsymbol{I}_{d u c}$ \\
\hline 0 & 19.79 & 62.20 & 66.40 & 247 & 291.18 & 417.99 & 101.87 & 2.49 & 0.16 & 2.69 \\
\hline 0.01 & 16.14 & 49.50 & 54.20 & 185 & 258.50 & 365.62 & 90.05 & 2.04 & 0.15 & 2.16 \\
\hline 0.02 & 13.62 & 40.40 & 45.70 & 165 & 233.45 & 328.45 & 80.35 & 1.72 & 0.14 & 1.80 \\
\hline 0.03 & 12.04 & 34.10 & 40.40 & 153 & 209.25 & 295.97 & 73.32 & 1.53 & 0.13 & 1.58 \\
\hline
\end{tabular}


Abbas Moustafa, Alshaymaa Ameen, damage analysis of inelastic structures under train-induced ....

\section{Table 4.}

Influence of hardening ratio on cumulative damage indices for SDOF inelastic structure $(\xi=0.05)$

\begin{tabular}{|c|c|c|}
\hline $\boldsymbol{\gamma}$ & $\boldsymbol{I}_{\boldsymbol{P A}}$ & $\boldsymbol{I}_{\boldsymbol{C F}}$ \\
\hline 0 & 43.36 & 41.37 \\
\hline 0.01 & 35.43 & 37.03 \\
\hline 0.02 & 29.99 & 33.46 \\
\hline 0.03 & 26.56 & 29.99 \\
\hline
\end{tabular}

Table 5.

Influence of $\beta$ on damage indices for SDOF inelastic structure $(\xi=0.05, \gamma=0.05)$

\begin{tabular}{|c|c|}
\hline $\boldsymbol{\beta}$ & $\boldsymbol{D I}_{\boldsymbol{P A}}$ \\
\hline 0.20 & 1.34 \\
\hline 0.30 & 1.36 \\
\hline 0.40 & 1.38 \\
\hline
\end{tabular}

Table 6.

Influence of yield strength $\left(f_{y}\right)$ on response of SDOF inelastic structure $(\xi=0.05, \gamma=0.05)$

\begin{tabular}{|c|c|c|c|c|c|c|c|c|c|}
\hline $\begin{array}{l}f_{y} \\
(N)\end{array}$ & $\mu_{\max }$ & $\begin{array}{c}u_{\max } \\
\times 10^{-3} \\
(m)\end{array}$ & $N_{r v}$ & $\begin{array}{l}E_{y \max } \\
(N . m)\end{array}$ & $\begin{array}{l}E_{I \max } \\
(N . m)\end{array}$ & $\begin{array}{c}E_{D \max } \\
(N . m)\end{array}$ & $D I_{P A}$ & $D I_{C F}$ & $D I_{d u c}$ \\
\hline $2.5 \times 10^{3}$ & 37.82 & 64.00 & 738 & 296.22 & 445.27 & 126.59 & 4.84 & 0.82 & 5.26 \\
\hline $5.0 \times 10^{3}$ & 10.50 & 35.20 & 137 & 183.87 & 259.95 & 65.12 & 1.33 & 0.16 & 1.36 \\
\hline $1.0 \times 10^{4}$ & 2.70 & 18.00 & 39 & 114.33 & 193.79 & 79.94 & 0.35 & 0.09 & 0.24 \\
\hline
\end{tabular}


JES, Assiut University, Faculty of Engineering, Vol. 45, No. 3, May 2017, pp.284-300

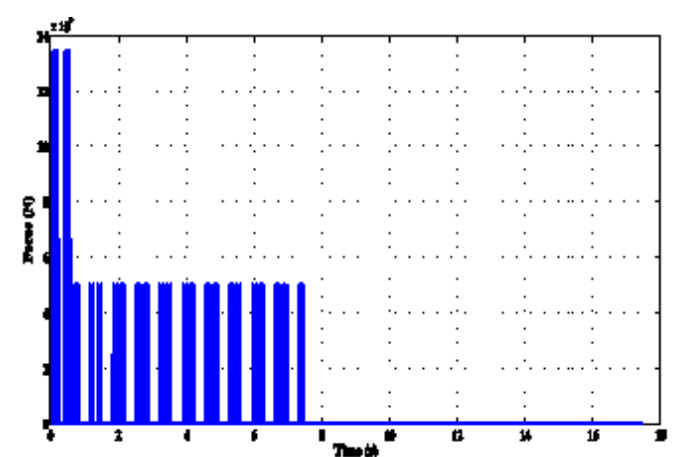

(a)

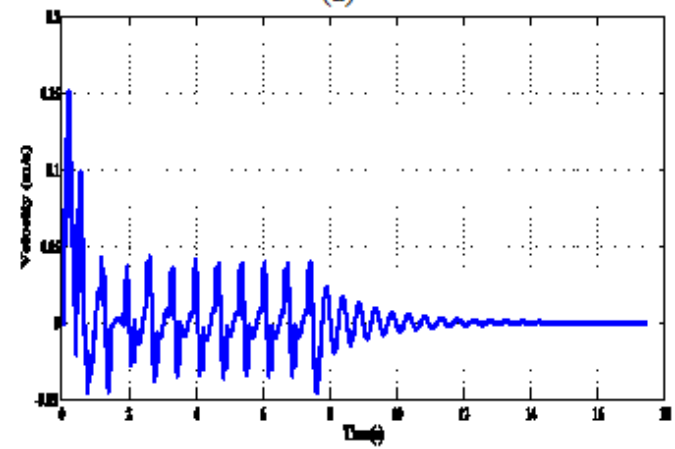

(c)

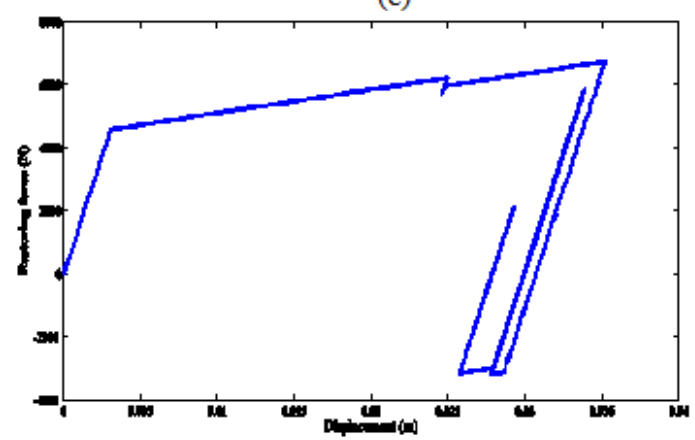

(e)

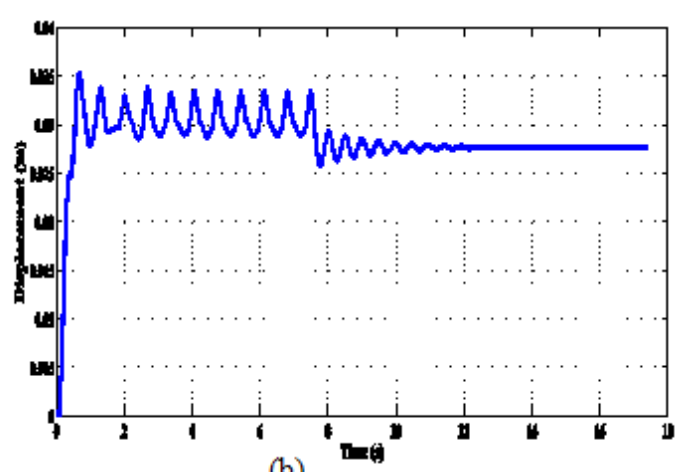

(b)

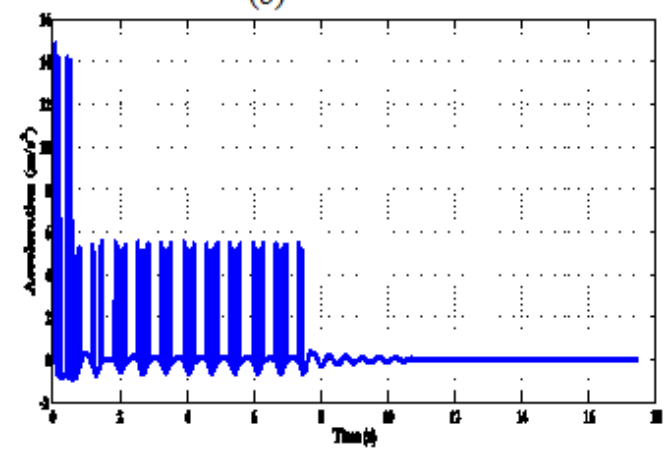

(d)

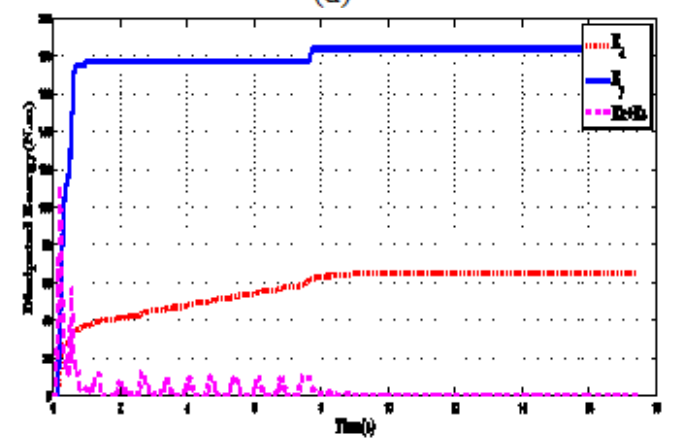

(f)

Fig. 5. Input train load and associated inelastic structural response $(\gamma=0.05, \xi=0.05)$ (a) Train input force (b) Displacement response (c) Velocity response (d) Acceleration(e) Hysteretic loop (f) Dissipated energy. 
Abbas Moustafa, Alshaymaa Ameen, damage analysis of inelastic structures under train-induced ....

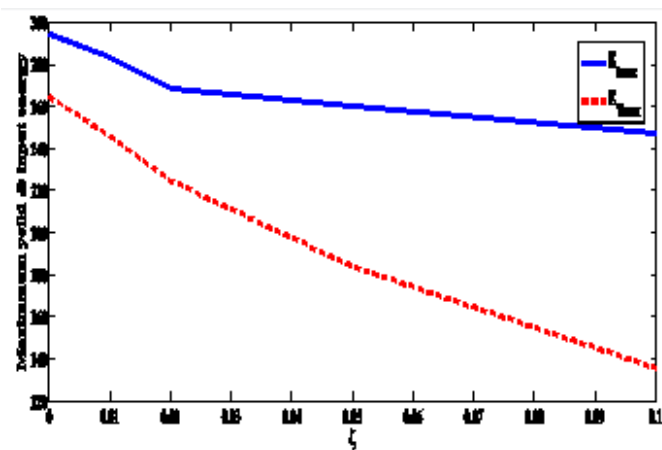

(a)

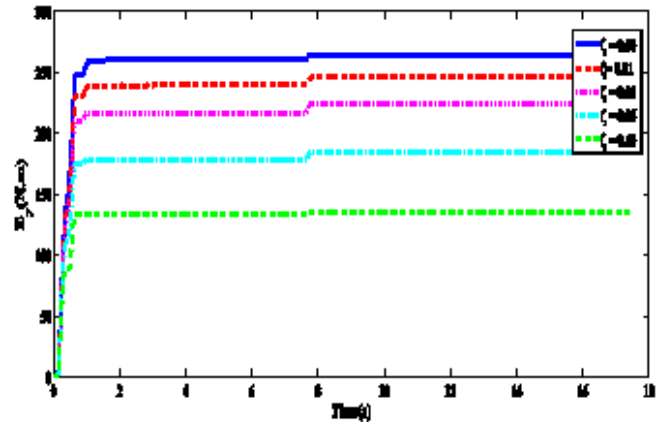

(c)

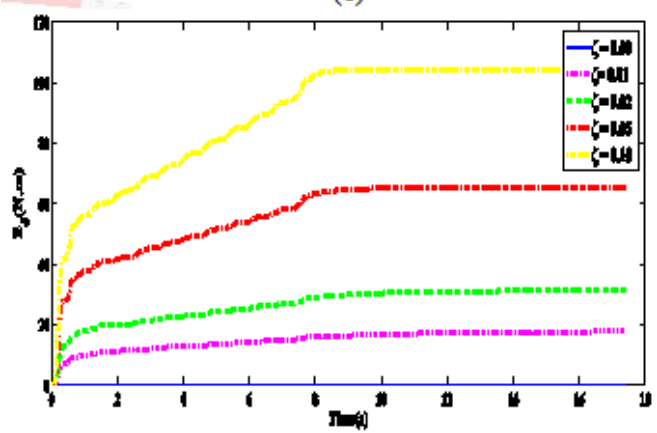

(e)

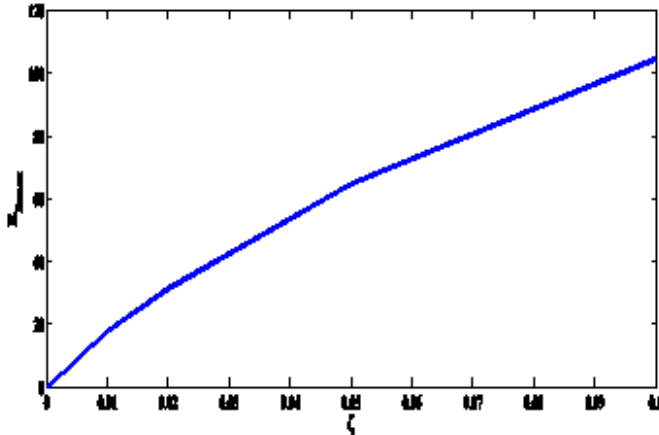

(b)

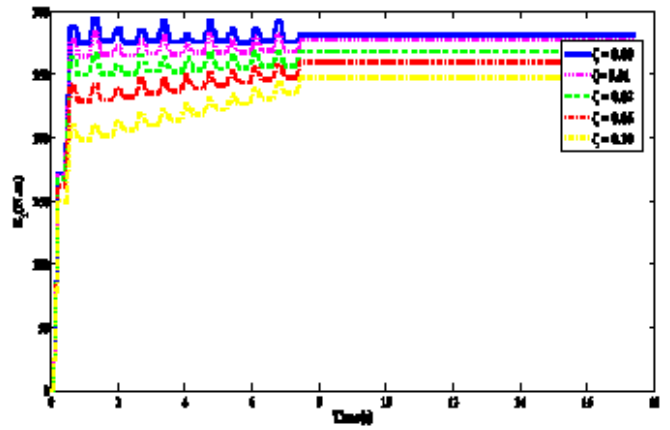

(d)

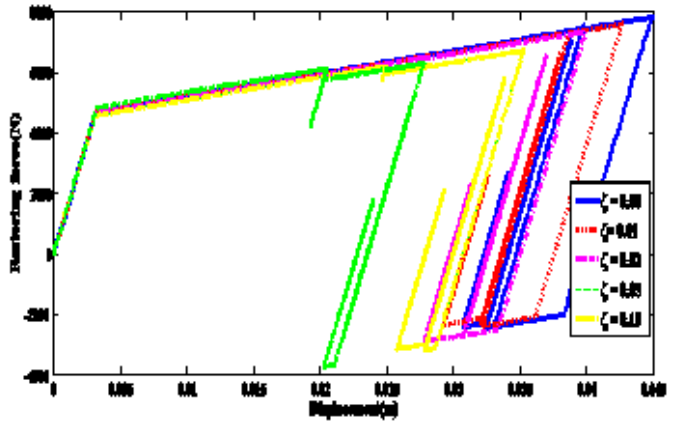

(f)

Fig. 6. Influence of damping ratio on response of inelastic SDOF structure $(\gamma=0.05)$ : (a) Maximum input and yield energy (b) Maximum damping energy (c) Yield energy (d) Input energy (e) Damping energy (f) Hysteretic loop.

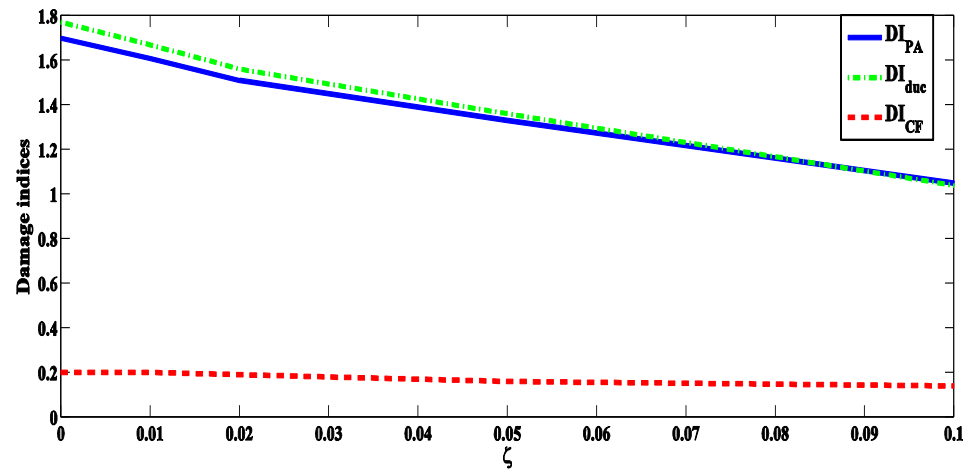

Fig. 7. Influence of damping ratio on Park and Ang damage index, Cosenza and Fajfar damage index and Ductility damage index for SDOF inelastic structure $(\gamma=0.05)$. 


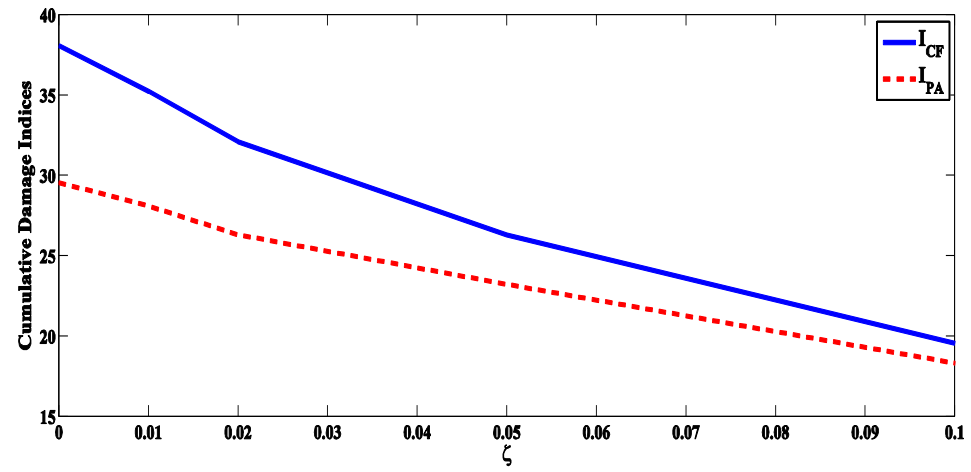

Fig. 8. Influence of damping ratio on cumulative damage indices for $\operatorname{SDOF}$ inelastic structure $(\gamma=0.05)$.

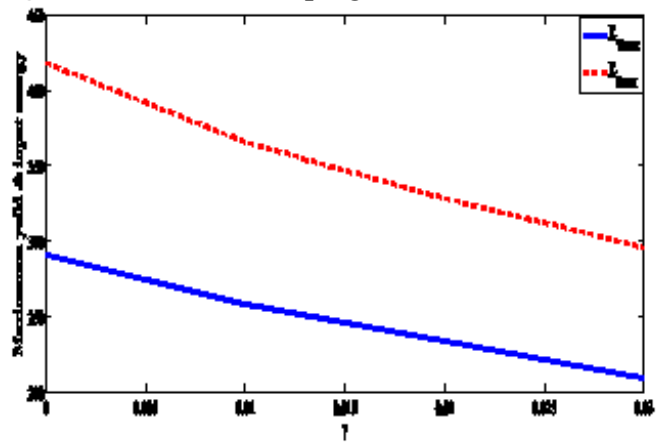

(a)

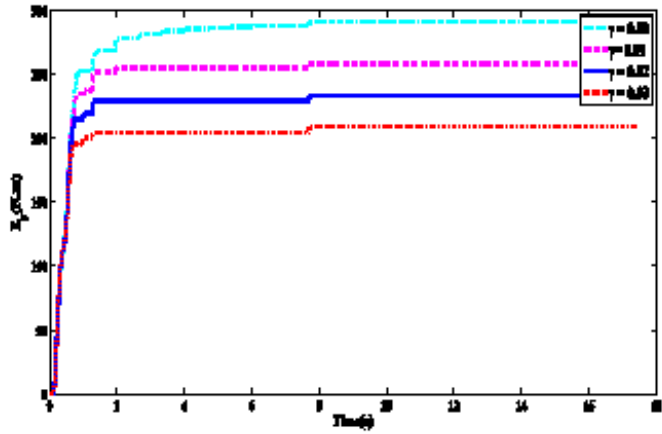

(c)

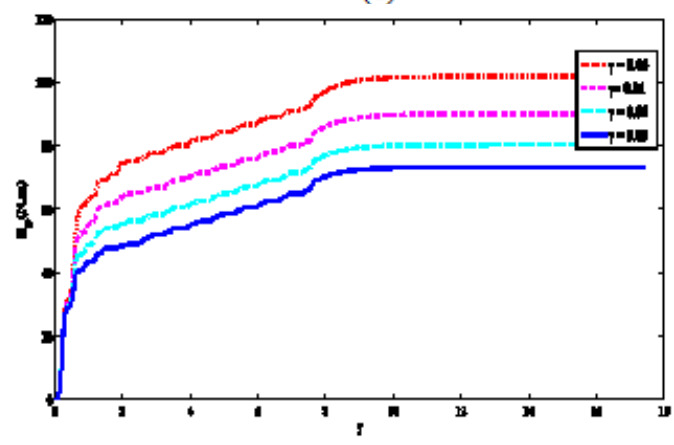

(e)

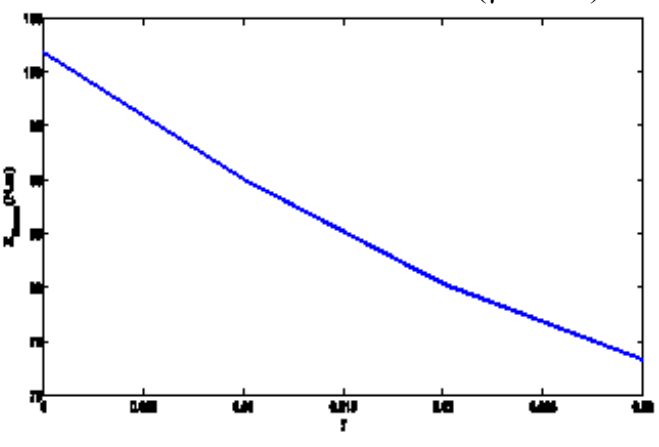

(b)

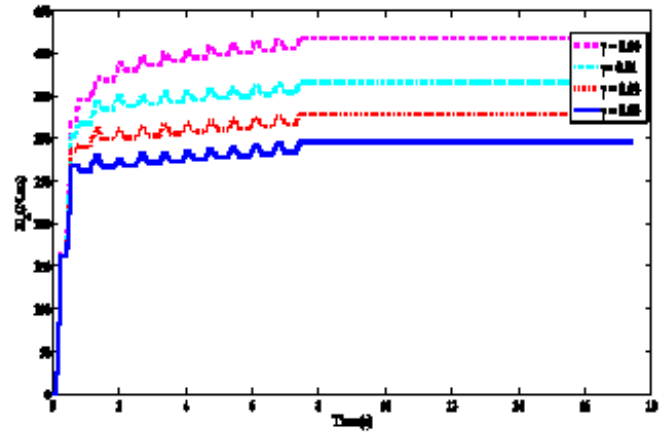

(d)

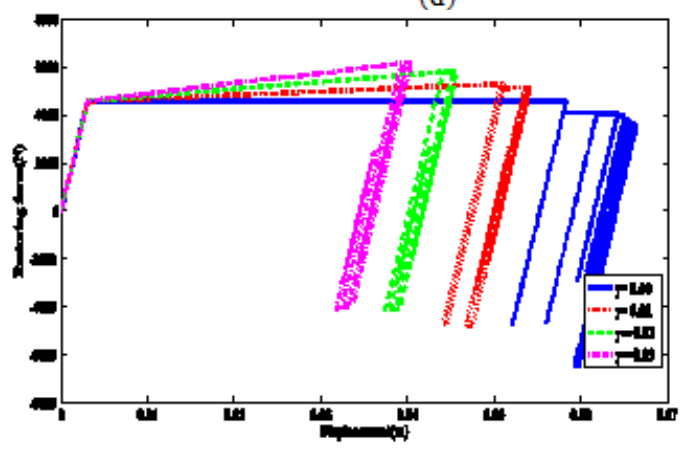

(f)

Fig. 9. Influence of strain-hardening ratio on response of inelastic SDOF structure $(\xi=0.05)$ (a) Maximum input and yield energy (b) Maximum damping energy (c) Yield energy (d) Input energy (e) Effect of $\gamma$ on damping energy (f) hysteretic loop. 
Abbas Moustafa, Alshaymaa Ameen, damage analysis of inelastic structures under train-induced ....

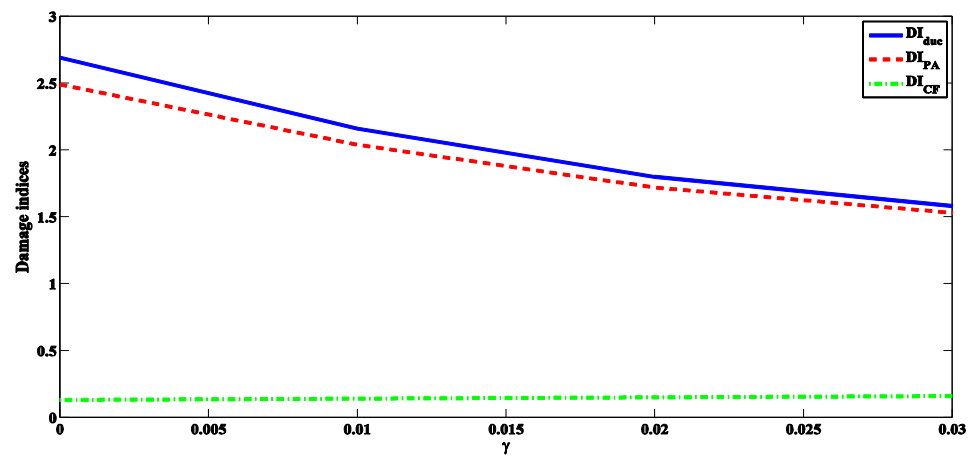

Fig. 10. Influence of strain-hardening ratio on Park and Ang, Cosenza and Fajfar and ductility damage indices for SDOF inelastic structure $(\xi=0.05)$.

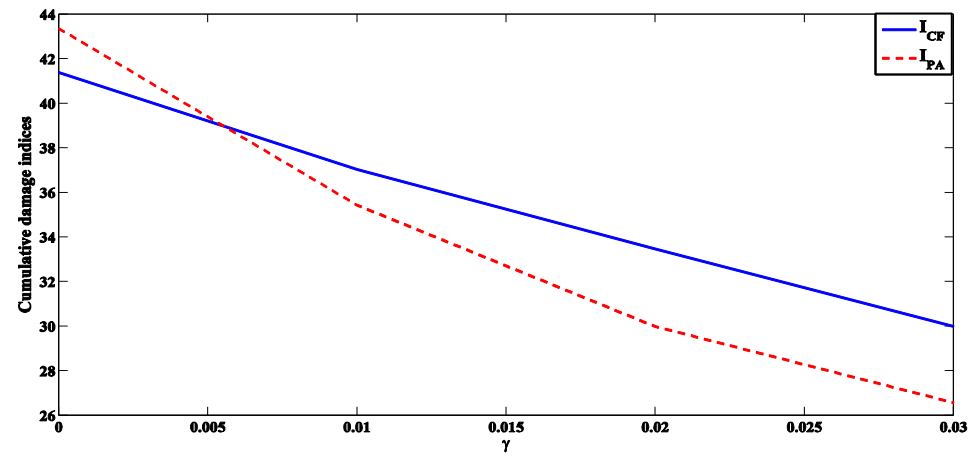

Fig. 11. Influence of strain-hardening ratio on cumulative damage indices for SDOF.

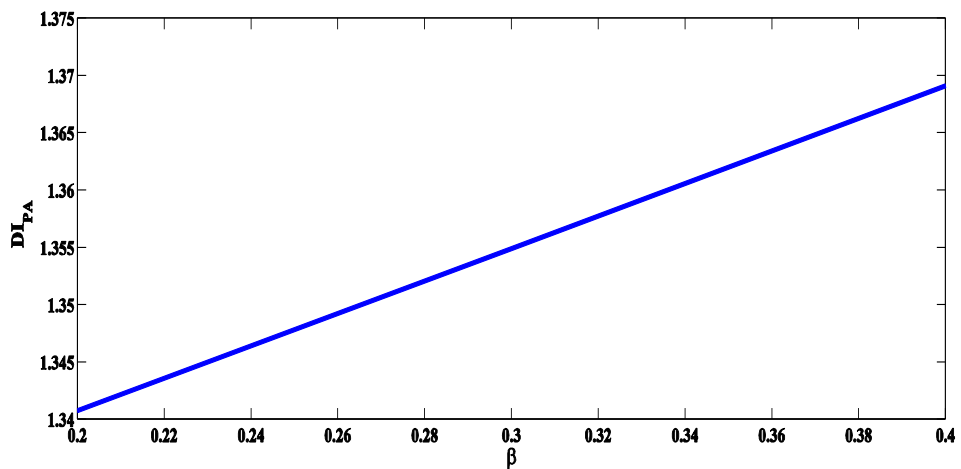

Fig. 12. Influence of $\beta$ on Park and Ang damage index for SDOF inelastic structure $(\xi=0.05, \gamma=0.05)$.

\section{Conclusions}

The response of inelastic SDOF structures under train-induced vibration is studied in this paper. The train load is modeled as a time-variant pulse function of unequal amplitudes. The train consists of a locomotive of 6 equal wheel axles and 10 coaches of 4 equal wheel axles. The objective of the study is to investigate influences of the structural properties and load characteristics on response of inelastic SDOF structures and associated damage level. The structure force-displacement relation is modeled as elastic-plastic or bilinear. The structural response is quantified using ductility, permanent and maximum deformations, and damping and hysteretic energies. Measures of the structure performance based on energy concepts and damage indices are also studied. Specifically, the structural performance is quantified in terms of Park and Ang, and Cosenza and Fajfar damage 
indices. Damage indices imply that the structure is damaged by a combination of repeated stress reversals and high-stress excursions. Moreover, the use of damage indices provides a measure on the structure damage level. A computational code is developed [33]. The formulation is demonstrated by studying the structural response of SDOF inelastic structure to pulse train load composed of a locomotive and 10 coaches.

Several aspects which are relevant to the problem are investigated. It is shown that the structural response (deformation, ductility, dissipated yield and damping energies and damage indices) under train-induced vibration depends on properties of the inelastic structure and load characteristics. Additionally, the response for the inelastic structure differs from that for the elastic structure. Unlike the elastic structure, the inelastic system after it has yielded does not oscillate about its initial equilibrium position. Yielding causes the structure to drift from its initial equilibrium position and the structure oscillates around a new equilibrium position until it gets shifted by another new yield. The study, examined influences of the variations of the structure yield strength, damping ratio and strainhardening ratio on the associated structural response. The damping ratio is seen to be directly proportion to the energy dissipated damping and inversely proportional to the yield energy and damage indices. Conversely, the strain-hardening ratio is seen to be directly proportional to the hysteretic energy dissipated by yielding and inversely proportional to energy absorbed by damping. The new scalar parameters proposed in this study in terms of cumulative hysteretic and cumulative damage index are believed to be of importance in quantifying energy absorption and damage of inelastic structures such as industrial installations under train-induced vibration.

The damage indices employed in the current work developed by Park and Ang and Cosenza and Fajfar were developed to assess damage of structures under earthquake loads. It is of interest to calibrate these damage indices and develop new damage indices for structural damage caused by other dynamic loads such as train-induced dynamic forces and blast forces resulting from explosions. Further research work accounting for more complex structures such as industrial installations and critical facilities such as security buildings and taking into account amplification of vibration waves in soil medium needs to be investigated. This can be carried out by integrating recently developed finite element software (OPENSEES, ANSYS, etc.). Finally, modeling of train-induced dynamic load using the framework of random vibration employing stochastic process is of great interest.

\section{REFERENCES}

[1] Akiyama, H. (1985). Earthquake-resistant limit-state design for buildings. University of Tokyo Press, Tokyo. 14(1):1-154.

[2] Auersch, L. (1994). Wave propagation in layered soil dynamics: theoretical solution in wave number domain and experimental results of hammer and railway traffic excitation. Journal of Sound and Vibration. 173(2):233-264.

[3] Auersch, L (2006). Two-and three-dimensional methods for the assessment of ballast mats, ballast plates and other isolators of railway vibrations. International Journal of Acoustics and Vibration. 11(3):167-176.

[4] CEN (2002). EN 1991-2, Eurocode 1: Actions on structures - Part 2: Traffic loads on bridges, Brussels.

[5] Clouteau, D. Degrande, G. and Lombaert, G. (2001). Numerical modelling of traffic induced vibrations. Meccanica. 36(4):401-420.

[6] Croy, I., Smith, M.G., Persson Waye, K.(2013). Effects of train noise and vibration on human heart rate during sleep: an experimental study. BMJ Open. 3(5):1-9. 
Abbas Moustafa, Alshaymaa Ameen, damage analysis of inelastic structures under train-induced ....

[7] Cosenza, C. Manfredi, G. and Ramasco, R. (1993). The use of damage functionals in earthquake engineering: a comparison between different methods. Earthquake Engineering and Structural Dynamics. 22(10):855-868.

[8] Fajfar, P. (1992). Equivalent ductility factors, taking into account low-cyclic fatigue. Earthquake Engineering and Structural Dynamics. 21(10):837-848.

[9] Francois, S. Lombaert, G. and Degrande, G. (2005). Local and global shape functions in a boundary element formulation for the calculation of traffic induced vibrations. Soil Dynamics and Earthquake Engineering. 25(5):839-856.

[10] Fryba, L (2000). A rough assessment of railway bridgesfor high speed trains. Engineering Structures. 23(5): 548-556.

[11] Garinei, A. and Risitano, G. (2008). Vibrations of railway bridges for high speed trains under moving loads varying in time. Engineering Structures. 30(3): 724-732.

[12] Ghobara, A., Abou-Elfath, H., and Biddah, A. (1999). Response based damage assessment of structures. Earthquake Engineering Structure Dynamic. 28(1):79-104.

[13] Hanazato, T. and Ugai, K. (1983). Analysis of traffic induced vibrations by FEM. Journal of Japanese Society of Soil Mechanics and Foundation Engineering. 23: 144-150.

[14] Hans, J.A. van Leeuwen and Aart, C. van Zwienen. (2016). The determination of railway vibrations levels in practice. Inter. noise, Hamburg.

[15] Hao, H., and Ang, T.C. (1998). Analytical modelling of traffic-induced ground vibrations. Journal of Engineering Mechanics-ASCE. 124(8):921-928.

[16] Hao, H., Ang, T.C., and Shen, J. (2001). Building vibration to traffic-induced ground motion. Building and Environment. 36(3):321-336.

[17] Hunt, H.E.M. (1991). Modelling of road vehicles for calculation of traffic-induced ground vibration as a random process. Journal of Sound and Vibration. 144(1):41-51.

[18] Kalkan, E., and Kunnath, S. K. (2008). "Relevance of absolute and relative energy content in seismic evaluation of structures." Advances in Structural Engineering., 11(1), 1-18.

[19] Lombaert, G. Degrande, G. and Clouteau, D. (2000). Numerical modelling of free field traffic-induced vibrations. Soil Dynamics and Earthquake Engineering. 19(7):473-488.

[20] Majka, M. and Hartnett, M. (2008). Effects of speed, load and damping on the dynamic response of railway bridges and vehicles. Computers and Structures. 86(6): 556-572.

[21] Moustafa, A. (2011). Damage-based design earthquake loads for single-degree-of-freedom inelastic structures. Journal of Structural Engineering. 137(3):456-467.

[22] Museros, P., Romero, M.L. and Alarcon, E. (2002). Advances in the analysis of short span railway bridges for high-speed lines. Computers and Structures. 80(27): 2121-2132.

[23] Nelson, J.T, Saurenman, H.J. State-of-the-art review(1983): prediction and control of ground borne noise and vibration from rail transit trains, Report No. 00386300, National Technical Information Service, VA.

[24] Park, Y.J., Ang, A.H.S., and Wen, Y.K. (1985). Seismic damage analysis of reinforced concrete buildings. Journal of Structural Engineering. 111(4):740-57.

[25] Park, Y.J., and Ang, A.H.S. (1985). Mechanistic seismic damage model for reinforced concrete. Journal of Structural Engineering. 111(4):722-739.

[26] Park, Y.J., Ang, A.H.S. and Wen, Y.K. (1987). Damage limiting aseismic design of buildings. Earthquake Spectra. 3(1):1-26.

[27] Powell, G.H., and Allahabadi, R. (1988). Seismic damage predictions by deterministic

[28] Methods: concepts and procedures. Earthquake Engineering and Structural Dynamics. 16(5):719-734.

[29] Takewaki, I. (2004). Bound of earthquake input energy. Journal of Structural Engineering. 130(9): 1289-1297.

[30] Uang, C.M., and Bertero, V.V. (1990). Evaluation of seismic energy in structures. Earthquake Engineering and Structural Dynamics. 19(1):77-90.

[31] Watts, G.R. and Krylov, V.V. (2000). Ground-borne vibrations generated by vehicles crossing road humps and speed control cushions. Applied Acoustics. 59(3):221-236.

[32] Xu, A.X. Guo, Y.L. (2006). Microvibration control of coupled high tech equipment-building systems in vertical direction. International Journal of Solids and Structures. 43(21):6521-6534.

[33] Zahrah, T. F., and Hall,W. J. (1984). Earthquake energy absorption in SDOF structures. Journal of Structural Engineering. 110(8):1757-1772. 
تحليل تلف المنشآت غير المرنة تحت تأثير الإهتزازات الناتجة عن القطارات

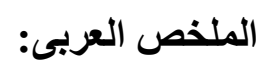

يتتاول هذا البحث تحليل إستجابة المنشآت الهندسية البسيطة غير المرنة تحت تأثنير الإهنزازات التهات الناتجة

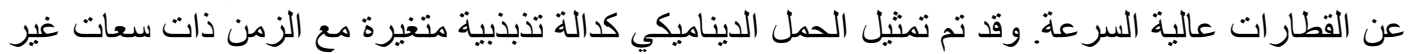

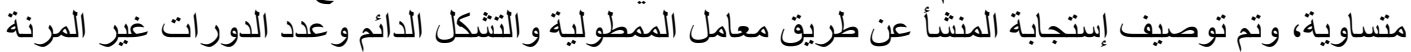

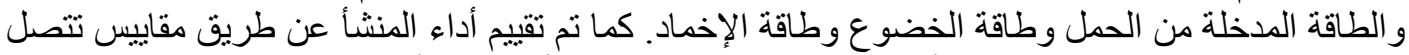

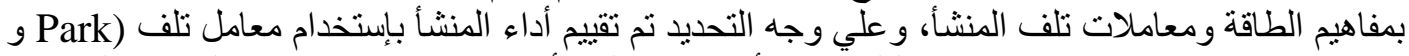

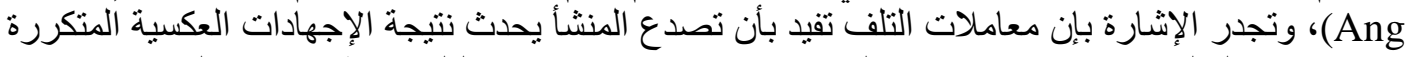

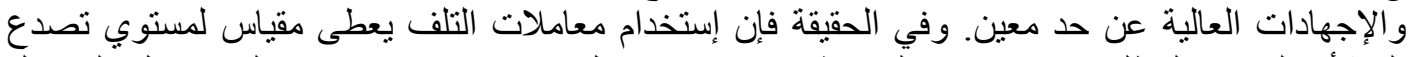

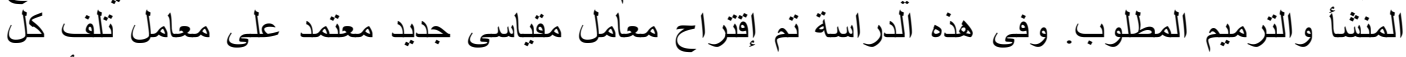

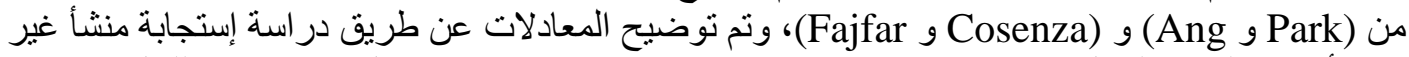
مرن أحادى الحرية لحمل قطار تذبذبى مكون من قاطرة و وشر ونر عربات. وتم عمل كود حسابي للحل بإستخدام برنامج Matlab لتوضيح نتائج الدر اسـة 